Article

\title{
Early Ideas in Underground Coal Gasification and Their Evolution
}

\author{
Alexander Y. Klimenko \\ School of Engineering, The University of Queensland, St. Lucia, QLD 4172, Australia; \\ E-Mail: a.klimenko@uq.edu.au
}

Received: 14 May 2009; in revised form: 10 June 2009 / Accepted: 12 June 2009 /

Published: 24 June 2009

\begin{abstract}
This article follows the development of early UCG (underground coal gasification) ideas. Historical facts are discussed mainly from the technological perspective and early experiments in UCG are analyzed. Our search for the first successful UCG experiment brings to light a new finding, which was commonly overlooked in previous reviews. We also outline the key role that engineer and inventor A. G. Betts played in introducing technologies utilizing unmined coal; his original ideas are visible in the first successful UCG experiments and in modern UCG technology.
\end{abstract}

Keywords: in situ utilization of coal; underground coal gasification; UCG development

\section{Introduction}

At the beginning of the 20th century, many industrial cities were covered by a heavy smoke — an unpleasant side effect of the coal-fueled industrial revolution. At that time, prominent British scientist Sir William Ramsay declared that the smoke menace could be defeated by ceasing the burning of coal, gasifying it underground in the bowels of Earth and using the syngas to supply our energy needs [1]. This process is now called underground coal gasification (UCG). Ramsay made this suggestion well before its time. The problem of smoke has become less severe in the second half of the 20th century. This positive change occurred partially due to technological improvements, and partially due to replacing coal with more benign fuels - oil and gas. UCG, whose development in the 20th century was constrained by discoveries of large oil and gas reserves, has not played any significant role in these improvements. History, however, tends to repeat itself and pollution over large cities in China indicates that the old 
smoke problem is coming back. This problem is less visible in older industrial nations, but no-one is immune. Even the Earth climate can now be affected by our always growing need for energy. Unless a principally new source of energy is miraculously discovered, mankind will have to burn more coal or curb its energy appetites. The current economic crisis represents only a mild version of economic pain that can be inflicted by disparity between energy supply and demand: laws of physics impose fundamental restrictions on economies that can not be adjusted by reserve banks in the same way as the cash flows. It seems that we may have to face again the problems that were daunting us 100 years ago, and the solution, also suggested 100 years ago — underground gasification of coal — can help.

UCG has numerous economic and environmental benefits [2]. Compared to conventional use of coal, UCG has the same advantages as above-ground gasification. At the same time, compared to aboveground gasification, UCG is much cheaper, does not disturb land by mining, leaves ash in its natural location and allows an operating UCG plant to promptly increase its syngas production at minimal capital cost. UCG seems to be the most suitable technology to be used in conjunction with geological storage of $\mathrm{CO}_{2}-$ geological conditions favorable for $\mathrm{UCG}$ are also favorable for $\mathrm{CO}_{2}$ storage [3]. $\mathrm{UCG}$ can be also combined with other relevant technologies such as synthetic fuel production and coal bed methane recovery. UCG was used on a large scale in the former USSR and tested in many countries. Minimal disturbance to land, reduction of air pollution and even a $25 \%$ reduction in $\mathrm{CO}_{2}$ production due to better energy utilization (as compared to conventional coal-fired power plants - see reference [2, 4]) are combined in UCG with the prospect of obtaining inexpensive energy and fuels from domestic sources [2]. While being a solution for many environmental problems, UCG has an environmental concern of its own — the possibility of groundwater contamination. However, the American UCG program of the 1970s and 1980s convincingly demonstrated that, if UCG sites are operated correctly, no contamination of groundwater occurs [5].

This article examines the early history of UCG. Although we have established new facts, the prime goal of this work is technical analysis of early plans and experiments in UCG. This period of UCG development is particularly interesting since it not only allows observing the established technology, but also enables analysis of particular choices made in this technology. In UCG, probably more so than in other industries, the same errors have been repeated over and over again mainly due to poor knowledge of historical facts and past experiences.

This is not the first article on early history of UCG. Reviews of early experiments have been given by many authors [6-8]. Among these publications, one review - by Olness and Gregg [7] - stands alone as by far the most comprehensive and detailed account of the first experiments in UCG. We, of course, do not intend to duplicate this work and instead focus on important events or details that are not covered in the review [7]. In this work, we also are interested in the technological motivations that drove the decisions made in the first experiments in UCG.

\section{Introducing the Idea of UCG: Siemens and Mendeleev}

The earliest recorded mention of the idea of gasifying coal underground belongs to Sir William Siemens, who suggested gasifying coal in situ (i.e. in the place of its natural location) in his address to the British Chemical Society [9]. Sir William was one of the Siemens brothers - prominent engineers who created the industrial empire that stretched across Europe from West to East and still bears their 
name. Werner, William and Carl Siemens were ennobled for services to three different countries (Germany, Britain and Russia). One of the inventions of the Siemens brothers was a coal gasifier (or gas producer if we use the terminology of the 19th century). William Siemens was particularly keen on this invention and advocated the benefits of wide use of the gasifiers for every possible application. There is only one paragraph in his speech that is dedicated to gasification in situ, where he suggests placing a gas producer into a mine and gasifying waste and slack coal underground, while delivering produced syngas to consumers at the surface through a piping system. Although placing a conventional gasifier in a mine does not seem like a particularly good idea due to fire dangers, the early Soviet program began with attempting construction of large chambers underground to gasify fractured coal, which was more or less in line with Siemens's idea.

The next mention of underground coal gasification belongs to Dimitri I. Mendeleev - the famous Russian chemist who invented the periodic table of elements. Multiple, but in most cases very short, remarks about the possibility and benefits of gasifying coal underground are scattered over his works. In his first remark on this issue, dated 1888 (reference [10], p. 66) he states that, in the future, coal will probably be gasified underground and, as practiced in America at that time, the gas will be delivered to consumers by pipes - this idea was not much different from Siemens's suggestion. Further remarks by Mendeleev indicate evolution of these thoughts and bring new light to the matter. In 1897, Mendeleev (reference [10], p. 351) suggests that gasifying unmined coal (without breaking it up) would save the labor cost associated with conventional mining and be most efficient from an economical perspective. The most visionary statement, however, was made by Mendeleev during his visit to the Kizel plant in 1899 (reference [11], pp. 540-546). The Kizel plant located in the Ural region of Russia produced iron and mined coal. Mendeleev noticed that underground fires were common in Ural. Kizel was also hit by underground fires which were successfully extinguished just before Mendeleev's arrival. He thought that it would be possible to exercise control over underground fires through several pipes, with one of these used to supply a limited amount of air and others to withdraw syngas by suction or through a natural flow. The director of the Kizel mine became excited about Mendeleev's ideas and intended to seek permission from the mine owners to conduct experiments.

Although there is no evidence that these experiments were ever attempted, the question of whether they could be successful if they were attempted is a reasonable one to ask. Mendeleev did not leave any drawings or descriptions of well configurations that could have been used in these experiments. If the wells were drilled from the surface into an area of the fire with an unknown configuration, it is unlikely that these experiments could have succeeded. Although syngas would have been produced in some spots, the probability of hitting the right spot with a production well is low. Thus, if these experiments had been conducted, it is most likely that they would have resulted in very low syngas quality with energy content close to zero or, in some instances, in syngas of appreciable but very unstable quality. Controlling this process blindly and using the technological base of the late 19th century would have been an impossible task. It might be the case that Mendeleev had a more specific design for the UCG trial in Kizel but there are no records that can confirm this. 


\section{A.G. Betts's Invention}

In 1910, three patents (American, Canadian and British [12-14]) were granted to American engineer Anson G. Betts for inventing a method of utilizing unmined coal. By his education, A.G. Betts was a chemists and Yale graduate who might well have been taught during his study by J.W. Gibbs. During the early stages of his career, Betts introduced many inventions and even wrote a book on using electrolysis to refine lead [15]. The role of A.G. Betts in inventing UCG was overshadowed, if not completely forgotten, by more famous figures (Siemens, Mendeleev and Ramsay) and unduly so, since his invention reads as remarkably insightful even according to modern standards. What did A.G. Betts suggest?

The three UCG patents are very similar in technical contents and offer several schemes of gasification of unmined coal. There is only one noticeable difference between the patents: the last patent (UK) distinguishes recovering firedamp (i.e. coal bed methane) and the subject of the invention - gasifying coal. The US and Canadian patents do not draw this distinction and may imply coal bed methane recovery as part of the process. Betts noted in his patents that, depending on configuration of the process, the produced gas can be significantly enriched by volatile components of coal.

Two of the Betts schemes, depicted in Figure 1, are the closest to modern views. The first scheme (Figure 2(a)) shows a gasification process of unmined coal seam 1 by air stream in a gallery connecting two shafts. Air is supplied through shaft 3 by the pumping plant 4 into passage 7 where the gasification process takes place. The produced gas is withdrawn through shaft 8 (or, Betts noted, one of the shafts can be replaced by a borehole) and delivered to the power plant 9 where it is converted into electricity. The power plant involves gas cleaning, a gas engine and a generator. Tar produced in the process is collected in well 11. An electric power line 5 is stretched from the power plant to drive the compressors. A view from above of a similar scheme (Figure 2(b)) offers various combinations of supplying air and withdrawing gas through shafts 13,14, 15 and 16, connected by two horizontal drifts 17 and 18. The plant 19 supplies air and either converts the produced syngas into electricity or cleans the gas and pumps it to an external consumer. The valves $21,22,24$ and 25 are used to control the process and achieve a preferred configuration of air supply and withdrawal. The method of gasification depicted in Figure 2(a) and 2(b) was later called stream gasification.

An alternative approach, now called the blind borehole method, is shown in Figure 2(c). Air and syngas are supplied and withdrawn through the same well (borehole) by using two concentric pipes: 32 for air supply and 31 for syngas withdrawal. The sketch of the injection nozzle 35 introduces the idea of directional injection, which as was proved much later in Soviet experiments, has a positive effect on the quality of syngas. In the blind borehole method, there is no need to undertake any labor underground and the whole process is controlled from the surface. Betts understood that using a single well inevitably limits the volume of coal subject to gasification to the vicinity of the well and suggested, as the gasified space widens, to continue gasification by using an additional well 38 (Figure 2(c)). In this case gasification is conducted between the two wells 31 and 38 connected without underground labor. The other wells can be added as needed. 
Figure 1. Underground gasification schemes proposed by Betts [12-14].

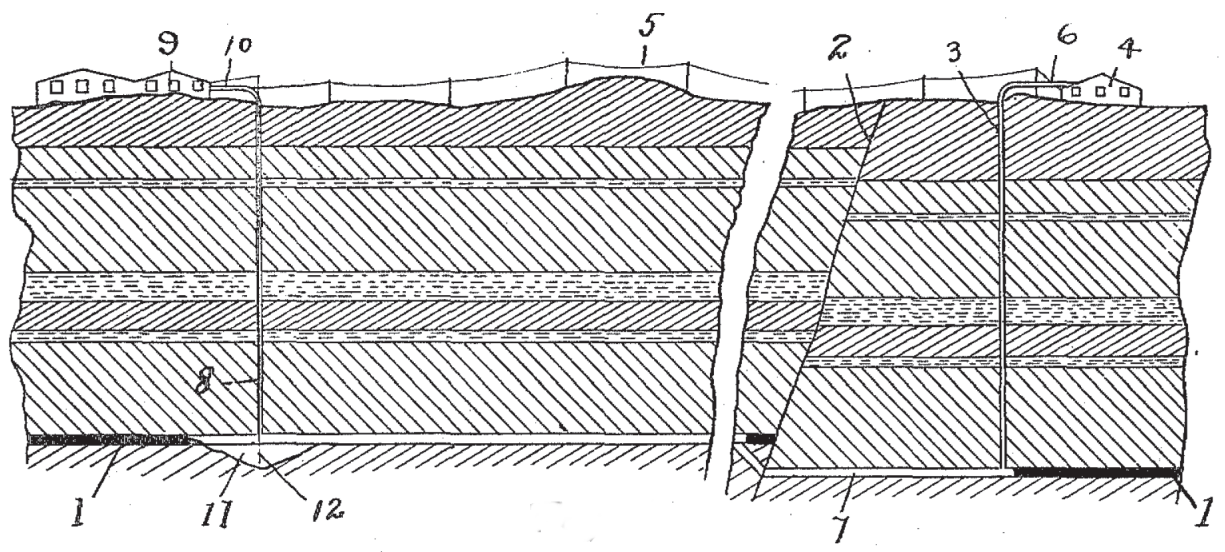

(a)

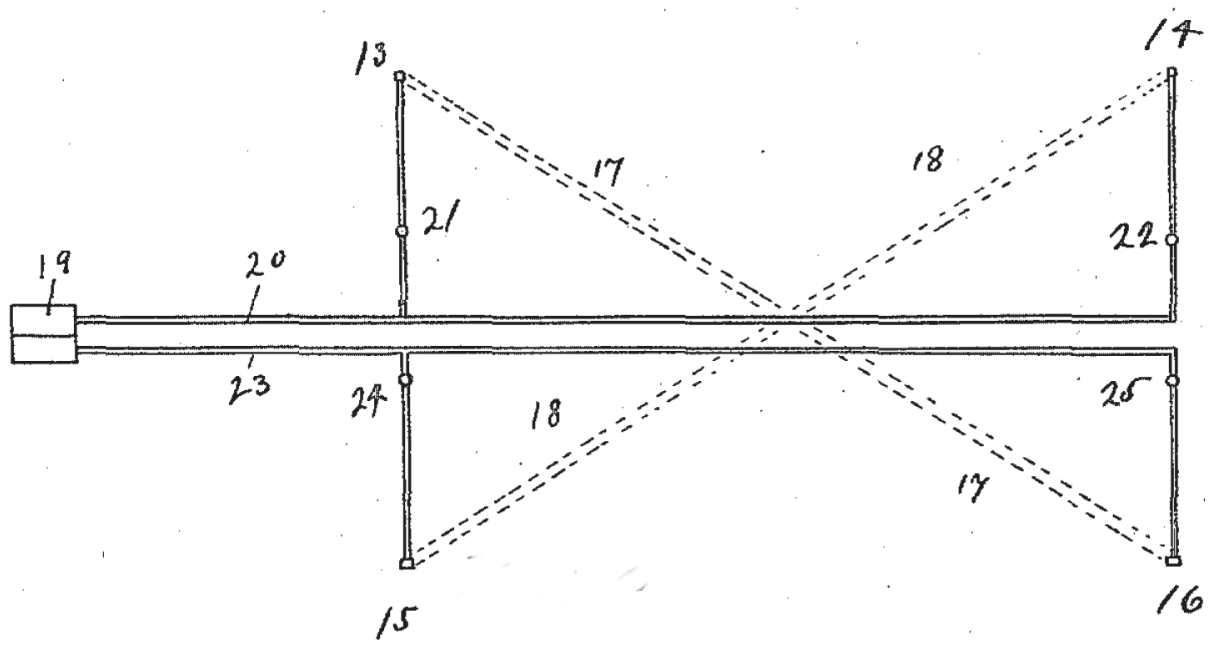

(b)

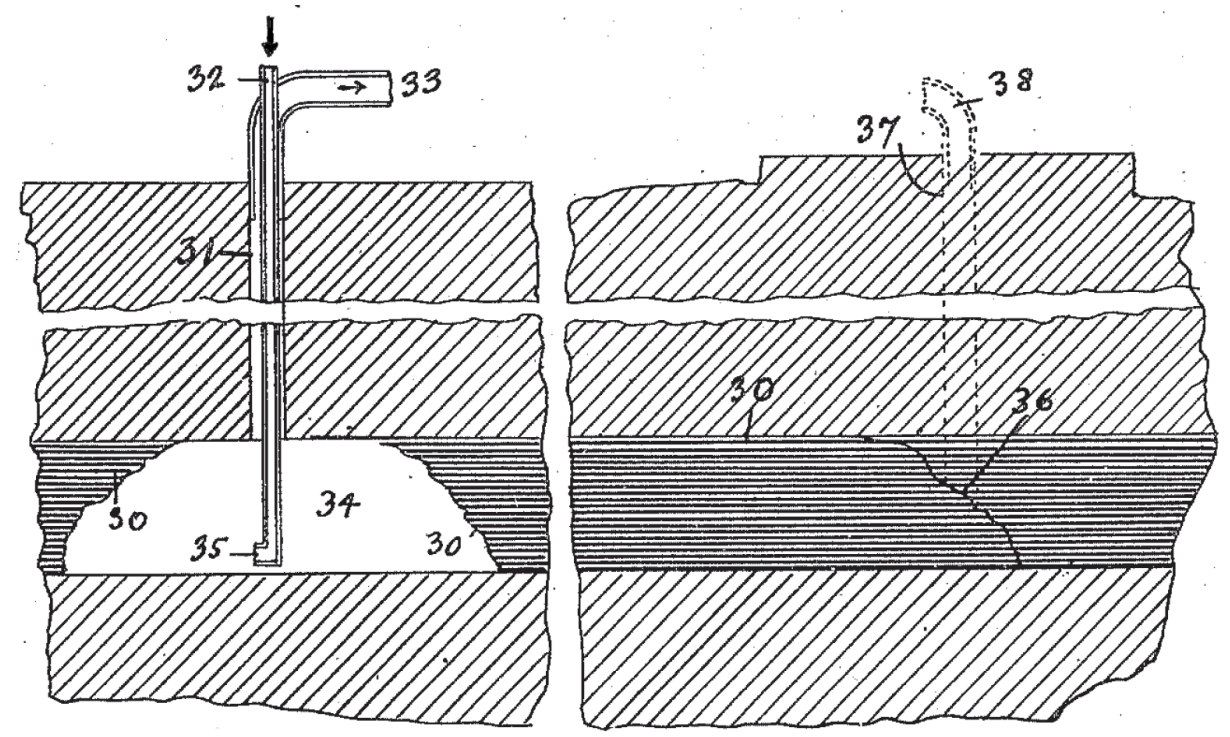

(c) 
In his patents, Betts also considers various factors that have later been proven to be important factors affecting gasification. Betts discusses subsidence and notes that, if subsidence causes cracks, this may create leaks of syngas but using negative pressures by sucking syngas from the production well would solve this problem. He notes that subsidence would have also a positive effect on gasification by filling the gasified space and improving contact between air and coal. Betts emphasizes the advantages of using several wells, allowing for a longer stretch of the gasification gallery. Betts anticipates a reduction of quality in the gas as the size of the underground cavity increases and suggests directional injection of air as a remedy, followed at later stages by switching air injection to new wells.

The question whether Betts's invention can work in principle would be rhetorical since we know that UCG technology, which was generally based on his invention, did work in multiple trials and, in the former USSR, on an industrial scale. More modern UCG technology, however, is not as simple as it may seem to be shown in the figures, and we need to pay attention to some details. A large fault, as shown in Figure 2(a), would be highly undesirable and in practice can impede gasification. The way of controlling subsidence is not clear from Figure 2(a) but is more prominent in Figure 2(b). We note however, that the triangular scheme shown in Figure 2(b) would leave large areas of coal untouched by gasification since gasification should proceed either in one direction or the other. The large scale of the suggested scheme would require sufficiently high flow rates. If syngas suction is used then groundwater drainage would have to be utilized to prevent excessive influx of groundwater into the gasifier. Modern UCG would use the hydrostatic pressure of groundwater to lock gases within the cavity and pressure within the cavity to balance the water influx. The blind borehole method can work and produce syngas of a reasonable quality when the cavity is small. Overheating would be a problem in this method, but watercooling of the injection pipe can be used to tackle the problem. However, the quality of syngas would decline rapidly with growth of the cavity, especially when the flow forms irregular recirculating patterns. Continuing the gasification process to an extent that allows the cavity to reach another well (located at a reasonable distance from the original well) is unlikely to be possible (although forward combustion linking can be attempted under favorable conditions). Betts understood that productive gasification needs to be conducted between different wells ("the advantage of several holes to the surface ... is apparent", p. 1, reference [12]), but remote well-linking technologies were not available at that time. The birth and development of UCG technology, which is discussed in the following sections, is closely linked to the ideas of A.G. Betts.

\section{Sir William Ramsay and UCG}

In 1912, famous chemist Sir William Ramsay - the first Briton to win the Nobel prize in chemistry spoke at a luncheon that followed the opening of the International Smoke Abatement Exhibition in London [1]. At that time smoke was a severe problem in many industrial cities, and the exhibition attracted a lot of public attention around the world. Proposing for the success of the exhibition, Ramsay said that there is a way to abolish this smoke nuisance. Instead of burning coal, it can be gasified underground by drilling a borehole, firing coal, supplying air and extracting hydrogen and carbon monoxide. The produced gas then can be used to generate electricity. This would resolve many problems including air pollution and the ongoing strike of mining workers. In several months, Ramsay repeated the same suggestion at a dinner of the Institution of Mining Engineers, stating that gas, not coal, would be the fuel of 
the future and that the idea of UCG is going to be tested in Britain and in America [16]. His statements created an international surge of interest in UCG. A series of articles were published in newspapers and popular scientific journals, many of them crediting Ramsay with the idea and striving to obtain the details of what he said. Even V.I. Lenin - at that time marginal political figure living in exile - responded with an article praising Ramsay for his invention but scoring a political point that the fate of the mining workers would be different under communism [17].

Which scheme of underground gasification did Ramsay suggest? As was reported in Gas World [18], a 6-inch borehole was to be drilled into a coal seam with three concentric pipes: one for injection, one for syngas withdrawal and one for water drainage. Since water drainage from a volume heated up to more than $1000{ }^{\circ} \mathrm{C}$ seems impossible, one can assume that this pipe was in fact for cooling the injection system by recirculating water. One may note that this scheme is very similar to the method suggested by Betts (Figure 2(c)) - the only difference is the third pipe introduced in Ramsay proposals. In Soviet literature (for example see reference [19]), the scheme shown in Figure 3(a) was commonly and incorrectly referred to as the "Ramsay scheme" (dating the Betts patent in year 1930 is also a common mistake of early Soviet publications on UCG).

After his visit to America later in 1912, Ramsay began preparations to conduct the first UCG experiment. He convinced a prominent industrialist from North-Eastern England, Sir Hugh Bell, to support the trial [20]. The preparations began at Hett Hill near Tursdale Colliery in Durham (UK). According to Sir Hugh's son, Sir Maurice Bell, a six feet-wide shaft lined with reinforced concrete was sunk into a coal seam where it was joined (or was to be joined) with a drift [8]. The top coal seam in that area is the Low Main Seam. This seam is $60 \mathrm{~cm}$ thick and located at the depth of around $40 \mathrm{~m} \mathrm{[21].} \mathrm{The} \mathrm{other}$ seams of a comparable thickness are much deeper and it is most likely that the Low Main Seam was chosen for experiments. According to both Bells [8,20], the preparations were nearly completed but the experiments did not proceed forward due to the outbreak of the war in 1914 and Ramsay's death in 1916. Sir Hugh Bell was later looking for an enthusiastic person to continue the experiments but could not find anyone [20].

Although Ramsay's UCG experiments were not conducted, the question of whether they could have been successful remains. First we note that the actual experimental design was quite different from the UCG schemes previously advertised in the media. The actual plan had more similarities with Betts's shaft scheme (Figure 2(a)) than with the blind borehole scheme. It appears that Ramsay never attempted to implement the "Ramsay UCG scheme". Since a second shaft connected to the drift was not mentioned by Sir Maurice Bell, we can assume that a borehole was drilled (or planned to be drilled) at the other end of the drift (it is most unlikely that Ramsay could possibly forget this important detail; after all he was one of the most distinguished scientists of his time). The plan of Ramsay's experiment inferred from available information is depicted in Figure 3(b). Could Ramsay possibly succeed with his experiments? Assuming the drift had sufficient length and powerful compressors were at Ramsay's disposal to supply sufficient air flow rates, these experiments could produce syngas. The quality of syngas probably would not be particularly high due to small thickness of the seam but good draining of the gasification area could improve the outcomes. However, as the gasification proceeds further, the channel widens and roof collapses, the quality of syngas would inevitably decline. In principle, it is possible that Ramsay had a plan to tackle this problem although UCG is a complex technology and resolving all associated issues in 
a single trial would be unlikely. Overall, Ramsay's experiments could have become the first successful UCG trial in history if they were not interrupted by the war.

Ramsay's role and motivation in relation to UCG matters were, and probably still are, widely misunderstood. It is not commonly known that Ramsay was not only a distinguished scientist but also an industry consultant, a director of several companies and had essential business interests. Ramsay had a good knowledge of British patent system and repeatedly acted in courts as an expert witness[22]. His traditional biographers Tilden [23] and Travers [24] paid little attention to the business side of his career, though it was thoroughly investigated by Watson [22]. After Ramsay's death, Tilden undertook the task of writing a biographical book outlining Ramsay's life achievements; he searched the personal archive of Ramsay, which was lent to him by Lady Ramsay, and destroyed many documents related to Ramsay's industrial activities [22]. A careful reader of reference [23], though, would notice a hint of criticism related to Ramsay's industrial activities. In his book about Ramsay [23], Tilden mentioned in situ gasification only once.

Figure 2. Underground gasification schemes that were (a) mentioned [7, 19] and (b) used by Ramsay.

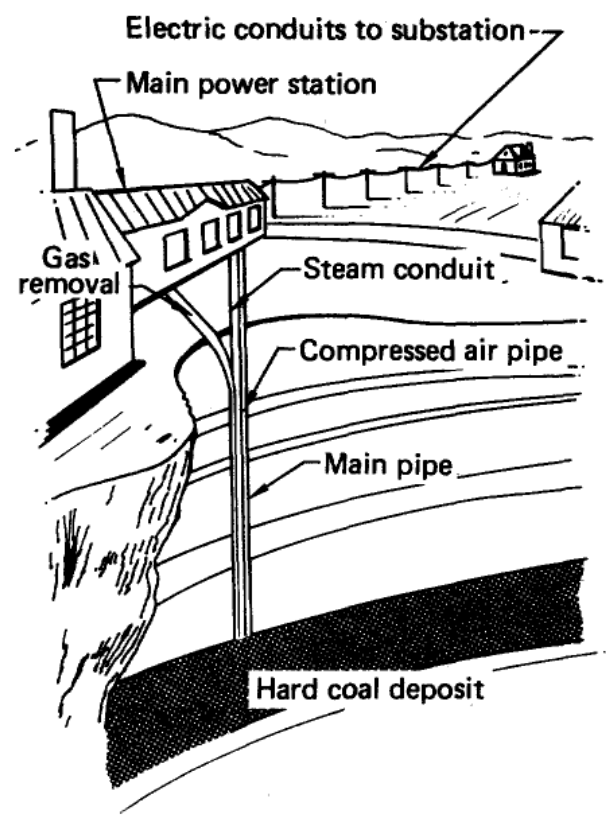

(a)

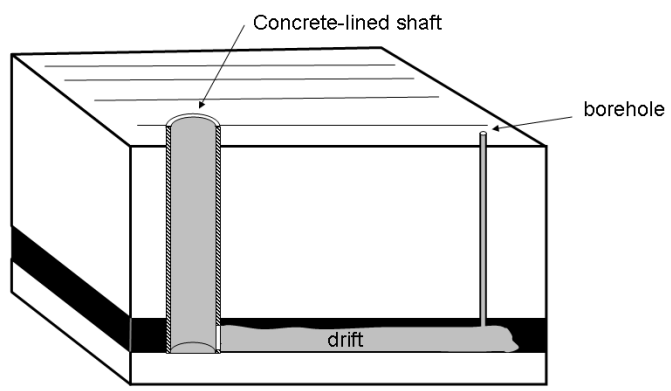

(b)

In 1912, Ramsay planned his retirement from being a Chair at the University College and spending more time on his other interests. The principal feasibility of UCG from the perspective of fundamental science was clear to Ramsay ("there is nothing new in that" — he noted in one of his interviews [18]). Ramsay saw UCG as an excellent technological opportunity for commercial development. The blind borehole approach would be the easiest to confirm the concept of UCG by experiments but, from a commercial point of view, this option is not particularly attractive due to the limited amount of coal that can be gasified from a single vertical well. Channel gasification uses two wells or shafts to extend the 
process over a much larger area, making this process very promising from an economic perspective. Ramsay opted for a larger trial and channel gasification to make it closer to possible industrial applications. When the war broke out, British economic priorities changed very quickly. Ramsay decided to abandon his UCG efforts and focus on his role of a director of Synthetic Production Company which became quite successful during the war period [22].

In a summary, we do not have any evidence that Ramsay invented or ever claimed to invent UCG. Ramsay did suggest to conduct UCG trial in UK and later led this effort but, it seems, did not claim any scientific innovation in this matter. Since Lenin annotated UCG as Ramsay's invention [17], this opinion later became indoctrinated in the Soviet system with a "correction" that he probably was enlightened by Mendeleev's remarks on UCG. Ramsay, however, never published any work on UCG and what is known today is only interpretation of Ramsay's conversations by the media. The gasification schemes that can be inferred from these conversations were similar to gasification schemes suggested by Betts. Katherine Watson (personal communication), who searched many documents related to the industrial activities of Ramsay, has not come across anything related to UCG. Documents clarifying Ramsay's role in UCG may never have existed or, possibly, were destroyed after his death. It seems that Ramsay was familiar with the Betts patent, although detailed investigation of this matter would not change our conclusions and is not likely to be productive. We conclude that the presumption that UCG was invented by Ramsay is not supported by historical facts, although Ramsay should be credited with making the ideas introduced by Betts known to the rest of the world and with planning the first experiment in UCG.

\section{First Soviet UCG Trials}

Although it is commonly known that the first UCG experiments were conducted in the early 1930s in the USSR, the task of nominating the first experiment that confirmed the feasibility of UCG is not simple. A successful UCG experiment needs to produce gas of a combustible quality from unmined coal in a controlled manner that allows the experiment to be reproduced. A detailed description of the first experiments in UCG is given in the excellent historic review of UCG by Olness and Gregg [7], although in several important instances our account and interpretation of the events differs from this work.

The first UCG experiment began on March 3, 1933 in the Moscow coal basin at Krutova mine using the chamber method [7, 25]. A section of coal seam $10 \times 10 \mathrm{~m}$, which is depicted in Figure 3, was separated from the rest of the seam by brick walls. Air was supplied by air blowers from one side and the produced gas was removed from the opposite side. The idea of the chamber method belonged to engineer Kirichenko, who began preparations for another experiment in Lisichansk much earlier than at Krutova, though, due to more thorough preparations, he started his work only in 1934. The experiment at Krutova was prepared quickly and poorly: the chamber was leaking, monitoring equipment was not installed at the site and the air blowers had insufficient power. After the beginning of the experiments, the produced gas contained no more than 5\% CO and 10-14\% oxygen. On March 10 an attempt was made to improve the process by breaking the coal. Several boreholes were drilled into the chamber and explosives were lowered through these boreholes and detonated. Gas samples were collected not only from the exhaust pipe but also from the boreholes. Gas analysis, conducted only after the experiment was completed, indicated that some of the samples taken from the boreholes had a much higher $\mathrm{CO}$ concentration of up to $12 \%$. The reported oxygen concentration [7] was still around $10-14 \%$ in these 
better quality samples (although increase in the $\mathrm{CO}$ fraction without decrease in the $\mathrm{O}_{2}$ fraction seems to be unlikely). Whether a better quality gas was present in some points of the gasification chamber or not, the gasification was not conducted in a controllable manner that would allow this experiment to be called successful. The opinion that the first UCG experiment at Krutova was unsuccessful is common in Soviet literature [25-27].

The second UCG experiment, which was also conducted using chamber method, commenced on November, 29, 1933 at Shakhty in Donetsk coal basin [25]. Instrumentation was significantly improved in this experiment. Gasification was attempted but did not proceed until a large channel was made in the chamber and packed with broken coal that was then ignited. Although the gas quality sampled from the exhaust pipe was poor, the borehole drilled into the channel produced syngas of a reasonable quality: the gas contained 7.7-13\% $\mathrm{CO}, 13-27 \% \mathrm{H}_{2}$ and $0.2-2 \% \mathrm{CH}_{4}$ [7]. It is arguable point that this process was to some extent controllable, although we need to note that it was different from UCG - gasification of unmined coal - as we understand it today. This process was equivalent to constructing a surface (Siemens) gasifier in situ as was originally suggested by Siemens. This point was repeatedly remarked in Soviet publications [25, 26]. The same can be said about all chamber methods, but the experiment in Shakhty is one that clearly can not qualify for conducting gasification of unmined coal.

Figure 3. Outlay of the first chamber experiment at Krutova mine [7].

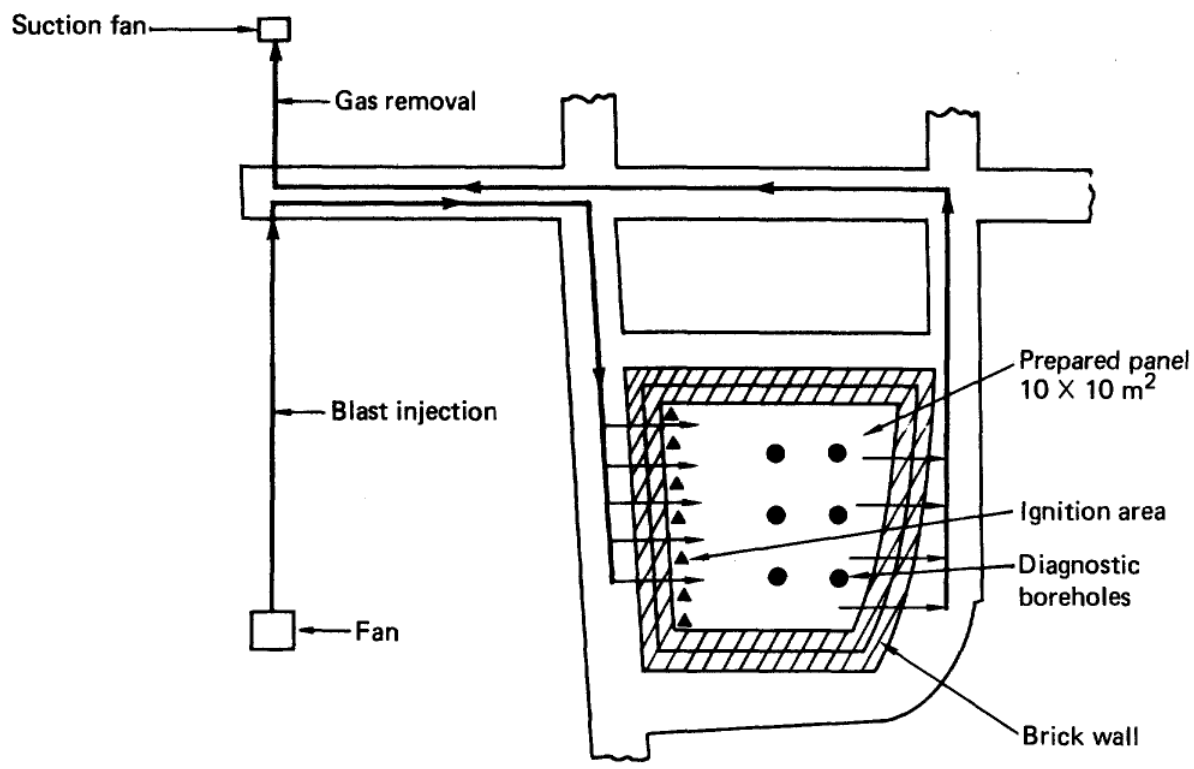

In Lisichansk, the group lead by engineer Kirichenko undertook an impressive effort in implementing the chamber method - his scheme of underground gasification. Coal seams in Lisichansk are steeply dipping. A $60 \times 30 \mathrm{~m}$ panel (which shown in Figure 4 as panel No. 1) was surrounded by an airtight wall and explosives were placed into the coal to break it up during gasification. Extensive instrumentation with controls from a single control center was installed at the site. Even an emergency shelter with independent air supply and a telephone was constructed underground near the gasification chamber. These preparations and the conduct of experiments were described by Kirichenko and Ton in great detail [28]. 
The experiments started on February 16, 1934 and did not result in a combustible gas for several months. Even when a high quality syngas was fed as a blast to the chamber on April 24, it was completely burnt there. The process in the chamber was that of complete combustion but not of gasification. Only in June was a combustible gas obtained, when one of the boreholes drilled into the gasification chamber from the surface (and not from the exhaust) was ignited at 19:45 on June 29 and burned for 15 days. During this period, the calorific value of the gas oscillated between 300 and $1800 \mathrm{kcal} / \mathrm{m}^{3}$ with an average around $1300 \mathrm{kcal} / \mathrm{m}^{3}$ (typical composition: 6-12\% CO, 7.8-20.6\% $\mathrm{H}_{2}$ and 2.8-4.2\% $\mathrm{CH}_{4}[7,28]$ ). On July 12 the flame was extinguished by the deteriorating quality of the gas.

Figure 4. Plan of the UCG experimental mine in Lisichansk [7, 28].

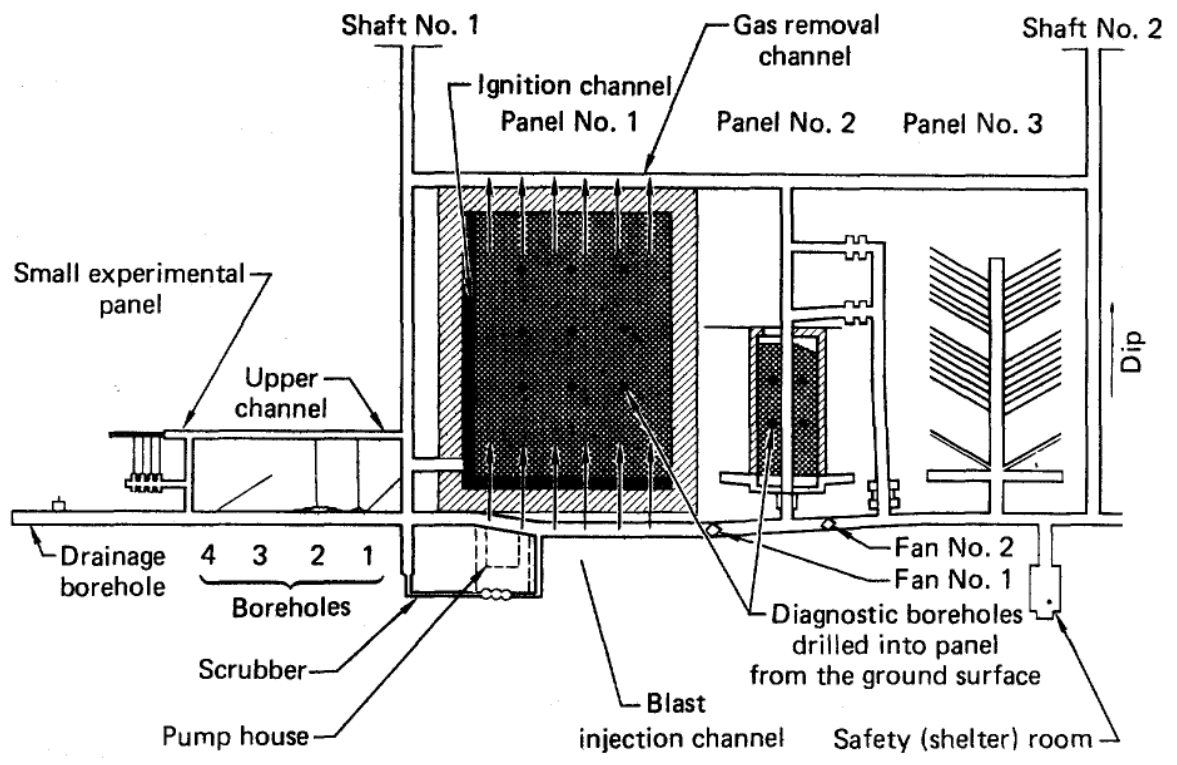

It may seem that this experiment represents the strongest case for being the first successful and controlled UCG test. The author of this article, nevertheless, believes that it was not. Although the Lisichansk experiment was prepared and conducted at an incomparably higher technological level that the experiments at Krutova, it did not result in a controlled UCG since the UCG process conducted in these experiments can not be controlled in principle. This process used forward combustion, which, as shown in reference [29], has instabilities. These instabilities resulted in fragmented combustion zones separated by colder areas. The location of these zones is essentially random and can not be predicted. Syngas is produced in the zones where the temperature is high but is then burned by oxygen flowing through colder areas. In principle, it is possible to drill a borehole into a "sweet spot" with a high concentration of $\mathrm{CO}$ but the chances of finding the right location are low and most of the produced gas would not have any combustible components. This "sweet" location was found in June after several months of unsuccessful operation. Finding this location by pure chance does not make this experiment repeatable.

The chamber experiment was followed by a series of borehole experiments that began in July in Lisichansk [28]. Conceptually, the borehole method represents a compromise between the chamber and stream methods. A large number of boreholes drilled in a coal block may be seen as a way of enhanc- 
ing the permeability of coal, while a single borehole can be seen as a reduced version of a gasification channel. The borehole methods may pose some technical problems, such as attaching air nozzles to each borehole, but, principally, gasification in a borehole can be controllable and results in syngas of a reasonable quality. Kirichenko and Ton [28] report many technical problems in conducting borehole experiments, which were then resolved one by one. After the first experiment on July 2, which was unsuccessful due to extensive gas leaks, the second borehole experiment on July 22 did produce combustible gas. The experiment began at 15:00 and in 40 minutes the produced gas was steadily burning with a blue flame. This borehole experiment can be easily reproduced (and actually was repeated in Lisichansk many times, although later the borehole method proved to be labor-intensive and impractical for UCG operations on larger scales). Was July 22, 1934 the beginning of successful UCG?

Another experiment using the stream method began on June 5, 1934 in Leninsk (Kuznetsk coal basin) [7, 25]. The experiment was led by engineer B.F. Grindler and conducted in a mine gallery encircling a section of coal seam, while the area on the other side of the gallery was previously subject to underground fire and collapsed. Air was supplied through one shaft and the produced gas was withdrawn from another shaft. The experiment was poorly equipped with instrumentation and the air blowers had insufficient capacity. During the first month of experiments, the produced gas contained little of the energy-containing components, but the process changed on July 2. Presumably, the roof collapsed and this closed oxygen bypass routes. The reported average gas composition measured between August 16 and 22 indicated that the syngas contained $25 \% \mathrm{CH}_{4}, 32 \% \mathrm{H}_{2}$ and $7.5 \% \mathrm{CO}$, and had a calorific value varying between 2000 and $5000 \mathrm{kcal} / \mathrm{m}^{3}$ [25]. The experiment was followed by a dispute between Grindler and another engineer, Alexeev and it seems that at times this dispute overstepped the limits of a technical discussion [30]. Although it is difficult to establish all details of the experiment, Alexeev could be right that a high content of methane in the product gas indicates intensive devolitalization and that the process was neither controlled nor understood. At the same time, Alexeev, who had his own UCG ideas based on the chamber method, did not see any benefits in stream gasification, which was advocated by Grindler. The following development of UCG clearly demonstrated that Alexeev was absolutely wrong on this. The favorable conditions for gasification in Leninsk after July 2 and the abnormally high concentration of methane in the syngas were more the result of good luck than planned strategy, and this experiment is not reproducible.

These UCG experiments were followed by a second round of chamber and borehole experiments in Shakhty, Krutova, and Lisichansk. While details of these experiments can be found in [7], our attention will focus on the earlier events that have somehow avoided wide coverage in the literature.

\section{The First Successes in UCG}

While the first chamber experiment (panel No. 1) in Lisichansk could not produce a gas with combustible components, Kirichenko and Ton [28] mentioned that a highly calorific gas was produced on April 24, 1934 using oxygen. While all other Lisichansk experiments were comprehensively reported by these authors, this obvious success deserved only a brief mention. The success of the experiment was not determined by the use of oxygen but by the gasification method. Previously, on April 17, oxygen was fed to the gasification chamber (panel No. 1) without any positive effect on the process but on April 24 not only combustible but highly calorific gas was obtained. This high-quality gas was produced by 
the stream method.

The mystery of producing high quality syngas on April 24 and being secretive about this has a rational explanation: Kirichenko and Ton [28] noted that the experiment was conducted under the technological auspices of the Donetsk Institute of Coal Chemistry (DUKhI). The DUKhI UCG group involved many UCG specialists (P.V. Skafa, V.A. Matveev, D.I. Filippov and others) who later became the leaders of the Soviet UCG program. A series of laboratory experiments were conducted at DUKhI using stream gasification in blocks of coal. It was commonly recognized that this group understood the UCG process better than anyone else [25, 26], yet DUKhI preferred not to publicize their results until a pilot UCG plant designed by DUKhI was put into operation. It needless to say that competition between different UCG groups was intense at that time and the question of making a discovery or only following the discoveries of others could be decided by days, not months.

How was the experiment on April 24 conducted? Sazonov [25] gives a brief description that blast was supplied to a coal face and a pipe was installed for withdrawal of produced gas. After placing unspecified ignition devices, the drift with access to coal face was closed with an airtight stopper. Oxygen was delivered from gas cylinders located at the surface. Pressure of the blast was gradually increased to $7 \mathrm{~atm}$ and the calorific value of the gas reached $2270 \mathrm{kcal} / \mathrm{m}^{3}$. The produced gas was delivered into panel No. 1 where it was burned. After 3 hours of stable operation the withdrawal pipe broke, most likely due to overheating and a high pressure. The results are given in the table taken from reference [25].

Table 1. Gas data from the first stream experiment in Lisichansk.

\begin{tabular}{llllllll}
\hline Time & $p(\mathrm{~atm})$ & $\mathrm{CO}_{2}$ & $\mathrm{O}_{2}$ & $\mathrm{C}_{n} \mathrm{H}_{m}$ & $\mathrm{CO}$ & $\mathrm{H}_{2}$ & $\mathrm{CH}_{4}$ \\
\hline $2: 40$ & 2.8 & 17.6 & 0.2 & - & 27.2 & - & - \\
$3: 20$ & 2.6 & 12.7 & 0.9 & 0.15 & 51.6 & 28 & 0.3 \\
$3: 40$ & 3.5 & 13.1 & 0.4 & 0.1 & 53.5 & 31.3 & 0.3 \\
$5: 00$ & 7 & 12.8 & 0.6 & 0.1 & 55.8 & 23.6 & 0 \\
\hline
\end{tabular}

Another DUKhI-designed experiment was conducted in Lisichansk on September 5-8, 1934 using the blind borehole method [25]. A $75 \mathrm{~mm}$ borehole was drilled from the surface along a steeply dipping coal seam. Oxygen was used to ignite the flame and then gasification was conducted with air. Syngas with a low calorific value was stably produced over 4 days and flared at the surface (the average calorific value was just above $600 \mathrm{kcal} / \mathrm{m}^{3}$ and the gas composition involved 6.6-12.7\% $\mathrm{CO}, 3.9-9 \% \mathrm{H}_{2}$ and $0-2.5 \%$ $\mathrm{CH}_{4}$ [25]). The process was terminated after the production pipe was burned. The exact outlay of the DUKhI experiment is not known, but a scheme for similar experiments can be found in another source.

Kirichenko, who obviously knew very well the plan of experiments conducted at his experimental site, discussed various schemes of underground gasification suggested by other people in reference [19]. The outlay, which fits the description of the experiment conducted on April 24, is taken from this publication and shown in Figure 5. This scheme has similarities with the Betts invention and with Ramsay's planned experiment. The drift must have been narrow - this in conjunction with high temperatures induced by the oxygen blast allowed the process to be stabilized quickly within the first hour. Generally supplying oxygen through the stopper and removing hot syngas through a pipe drilled to the surface is a more 
conventional option, but in this experiment oxygen was delivered from the surface and the syngas was utilized underground, hence the opposite arrangement is possible. It is highly unlikely, however, that the oxygen could be supplied and the produced gas withdrawn from the same side - this would dramatically reduce the quality of the syngas and in addition having oxygen and hot syngas in close proximity each other would represent a great safety concern, especially in a mine.

Kirichenko's article [19] also gives us a clue as to the likely purpose of conducting the second DUKhI Lisichansk experiment in September: he mentions that, according to Skafa's suggestion, a setup resembling the blind borehole method can be used to burn channels in coal. It seems that this idea was the main driving force behind this experiment - as a gasification method, the blind borehole scheme has significant limitations. In this experiment the borehole was drilled along the seam dip (but not across the seam as was originally suggested by Betts). Sazonov [25] prizes this experiment as a possible way of mining coal without underground labor.

Figure 5. Schematic of the stream experiment according to reference [19].

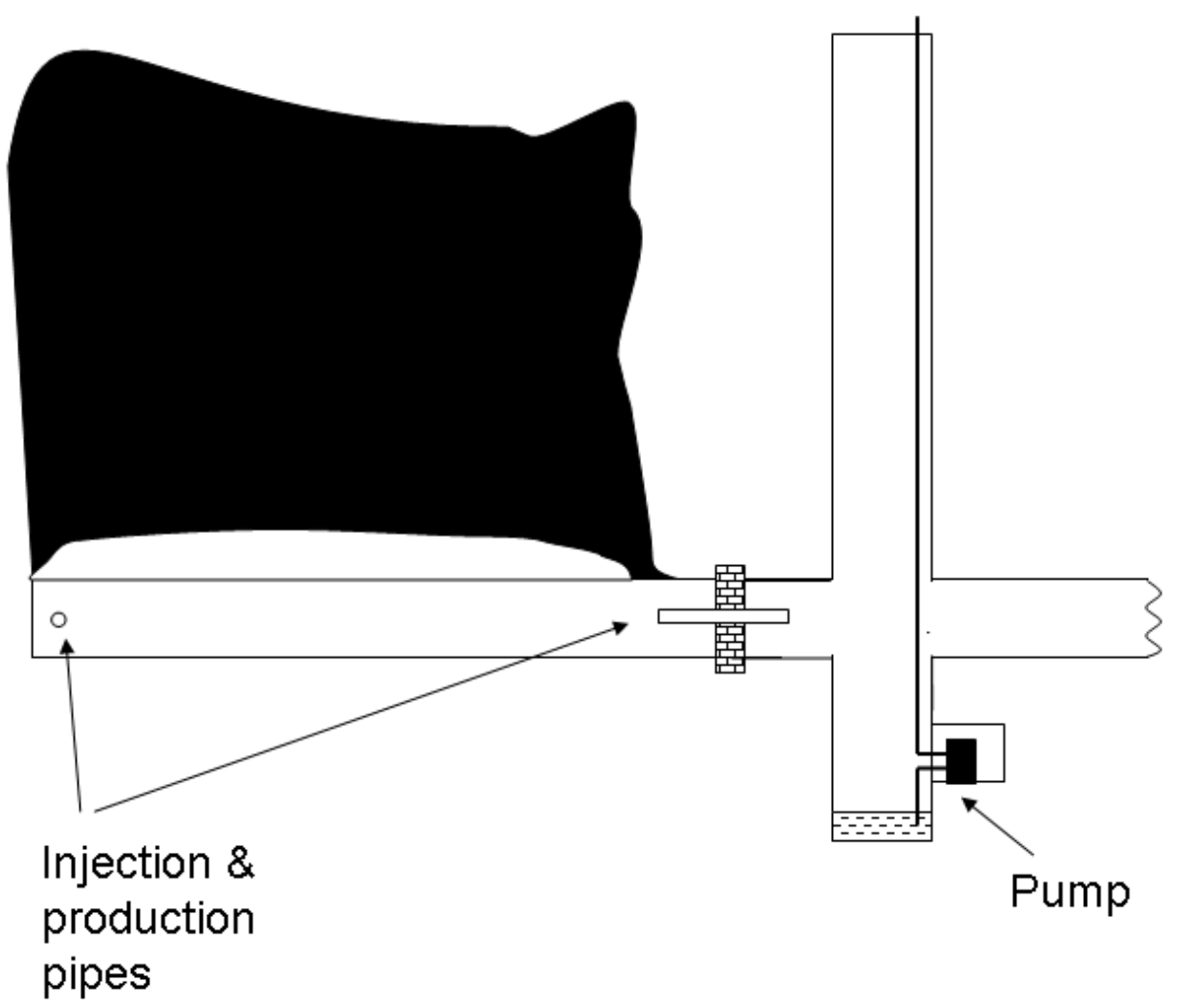

An early DUKhI experiment conducted in Lisichansk is also mentioned by Olness and Gregg [7]. According to this review, the experiment was conducted with oxygen for 3 hours on April 24, producing $2250 \mathrm{kcal} / \mathrm{m}^{3}$ gas but using the blind borehole method. No source of information was nominated. It seems that the two DUKhI experiments in Lisichansk were merged by mistake into a single experiment. The conclusion of reference [7] that the gas was produced by coal pyrolysis followed by cracking of higher hydrocarbons is not justified since the produced gas had a high $\mathrm{C} / \mathrm{H}$ ratio and it is difficult to 
imagine how consumption of carbon can be avoided at very high temperatures that are needed for thermocracking of methane.

A series of laboratory experiments emulating stream gasification were conducted in DUKhI. Since relative heat losses are large when the scale of experiments is small, DUKhI could become convinced after laboratory experiments that oxygen is needed for successful gasification. The underground experiments, however, are of larger scale and using oxygen can easily produce temperatures higher than desired. The oxygen experiment conducted on April 24 could have been easily reproduced and lasted longer with a lower fraction of oxygen in the blast or with some cooling of the production piping.

It may seem to be a mystery why this experiment, the most successful at that time, was not attempted again. Repeated experiments were not needed since the first experiment has already confirmed that a high quality gas can be obtained in UCG. The scheme used in this experiment, however, was not designed for a larger scale operation and the quality of gas would inevitably deteriorate after more coal is consumed. DUKhI was satisfied with the outcomes of the experiment and proceeded forward with design of an experimental pilot plant in Gorlovka based on a gasification method invented by DUKhI. We conclude that the first successful experiment in UCG was conducted in Lisichansk on April 24, 1934. Although this experiment lasted only 3 hours and was of a small scale, it produced syngas of a good quality directly from unmined coal and in a controllable manner, and this experiment could be easily reproduced even today. The history of UCG teaches us a valuable lesson. Kirichenko, whose outstanding professional credentials are beyond doubt, spent many years on inventing and preparing a large chamber experiment that, it seemed, was destined to become the first successful UCG experiment in history, while the success was achieved nearby in a much smaller and simpler setup.

The first pilot-style UCG operation was commenced in Gorlovka (Donetsk Basin) on February 8, 1935. The experiment was prepared and conducted by DUKhI and extensive instrumentation was installed at the site. The stream method used for steeply dipping seams in this experiment is depicted in Figure 6. This figure is taken from Soviet patent [31], which was filed in April, 1934 by the DUKhI UCG group but published only in 1938. This design may seem quite simple but it incorporated good understanding of the process, making it suitable for operations of larger scale. The whole panel surrounded by the channels was subject to gasification. As coal was consumed, the gasification process progressed upwards along the coal seam while the gasified space was closed by subsidence. The calorific value of the gas varied between 937 and $2472 \mathrm{kcal} / \mathrm{m}^{3}$ depending on the oxygen content in the blast. A larger scale of operation introduced new problems of controlling subsidence and the position of the fireface. Reversing the direction of the flow was used as one of the control options. The scale of the operation gradually grew and in 1937-1938 the produced gas was supplied to the local chemical plant.

In 1940, two other experimental stations using stream gasification were opened in Lisichansk (Donetsk Basin) and Tula (Moscow Basin). Although channels required for stream gasification were mined manually at that time, this was always considered to be a temporary measure by the Soviets. The ability of UCG to work at an industrial scale depended on eliminating costly underground labor. The opportunity to link wells by a channel without underground labor was found by chance at the Tula UCG station in 1941 [32]. It was noticed that while blast was supplied to one well, gas was produced from another well not linked to the first well by any gallery (due to the natural permeability of coal). This effect was used to establish a hydraulic link between wells and begin a shaftless operation between the wells. In 1947, 
Figure 6. DUKhI stream gasification method for steeply dipping seams [31].

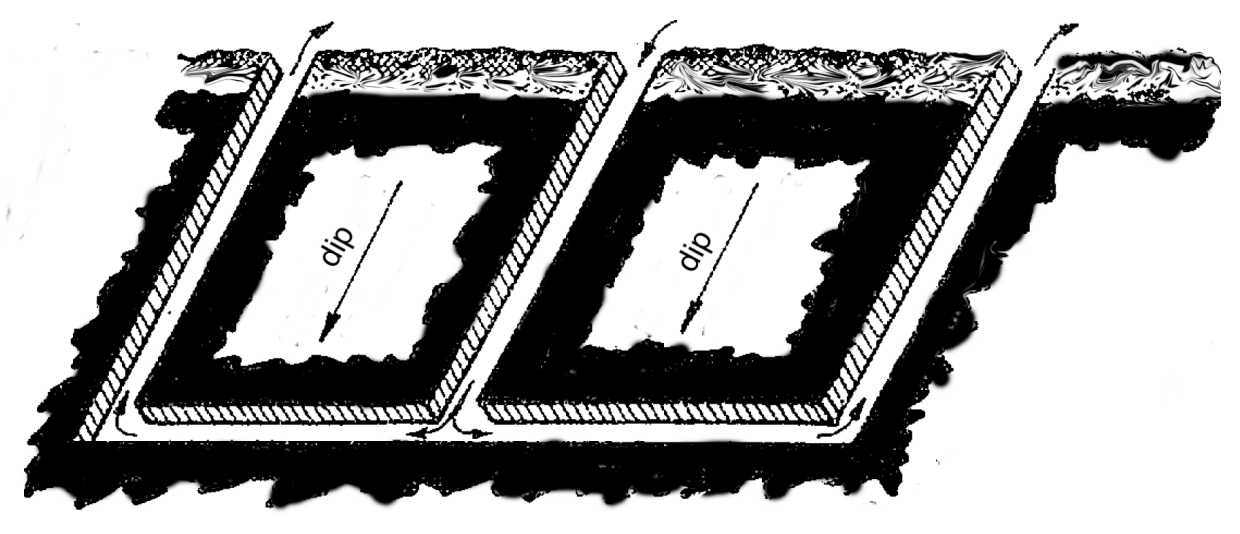

combustion linking was first performed for black coals (Lisichansk), although UCG with completely "no men underground" became an industrial reality only afterwards, in the mid-1950s.

\section{Further Developments}

Besides the Soviet UCG program, many counties conducted small UCG trials after WW2, but significant UCG efforts were undertaken during this period only by the UK and the U.S. The American program of 1947-1959 was carried out in Gorgas, Texas [6]. A number of British UCG trials was carried out at Newman Spinney (1949-1959) and Bayton (1950-1955) [33]. As the first Soviet UCG trials, these post-war efforts encountered significant difficulties. British engineers decided to ask for assistance from Soviet UCG experts and trial P5, carried out with Soviet assistance, was an immediate success, though the program was nevertheless terminated after this trial. The British Minister for energy cited the improved fuel situation as the reason [33].

The Soviet UCG program, however, was able to overcome the initial difficulties and by the end of the 1950s produced a technological base that was ready for application at an industrial scale. This technology did not need underground labor and was rapidly growing. The Soviets planned its further 50-fold expansion with a series of new UCG plants built. It must be noted that the Soviet UCG technology was workable but not perfect. Linking controlled from the surface imposed additional limitations on how UCG operations could be conducted and the quality of syngas was often well below the UCG potential. In the early 1960s, Soviet UCG production reached full industrial scale and was still increasing. Numerous gasification schemes, whose specification goes beyond the scope of the current work, were investigated. At the same time, large gas and oil reserves were discovered in the former USSR during this period and it became clear that the USSR possesses reserves of high-quality natural gas for hundreds of years; the UCG gas, which has much lower energy content, was not likely to be needed for the Soviet gasification program any time soon. In 1964, the Soviet government made a pragmatic decision and its UCG program was downgraded. Research institutes were redirected form UCG to natural gas, several UCG stations were closed and all new construction plans were cancelled. After the mid-60s, UCG production in USSR began to decline. UCG was moved to the sidelines of the Soviet system.

A most significant UCG effort, which is discussed in the next section, was undertaken in the USA in 
1970s and 1980s. A series of small but very deep (500 m-1 km) UCG trials was conducted in Europe in the 1980s and 1990s. China has carried out a series of UCG experiments in the late 20th century, although the exact scope and outcome of these experiments remain unknown.

\section{American UCG Program}

UCG has returned to the land of its inventor in 1973, only several years after the death of A.G. Betts. The American UCG program of 1973-1989 made a large impact on UCG technology. This effort was conducted or sponsored by DOE (Department of Energy) and its predecessors, and the UCG technology was significantly upgraded in a series of trials. The outline of this program and further references can be found in reference [34]. The UCG program of this period involved a careful study of the previous experiences including the series of UCG experiments in 1946-1959 at Gorgas, Alabama.

During the early American UCG trials at Gorgas, numerous difficulties were encountered in maintaining stable gas quality and in combating gas leaks. In spite of these difficulties, a process of connecting two wells with the assistance of electricity - electrolinking — was invented in these trials. This process uses high-voltage electricity to heat coal and, since the coal resistance decreases dramatically with increased temperature, electric current tends to concentrate within a narrow passage of high conductivity. The continuing supply of electric energy burns coal within this passage and a narrow channel is formed. Syngas is produced during electrolinking, although the main purpose of the process is forming a hydraulic link between two wells. Electrolinking proved to be efficient in certain conditions and was later used on a large scale at the Soviet UCG station near Tula.

Careful study of past mistakes produced an immediate success: the first trial near Hanna, Wyoming resulted in syngas of a high and stable quality, which was produced continuously over a period of six month. This location near Hanna became the site of a series of successful UCG experiments (Hanna I, II, III, IV and later Rocky Mountain I). More than 30 thousands tones of coal was gasified in these experiments. With the exception of the Rocky Mountain trial, air was used as a gasification agent in these experiments. The typical depth of these trials was just above $100 \mathrm{~m}$. The series of Hanna trials (Hanna I-IV) was completed with very encouraging technological and environmental results in 1979.

The possibility of gasifying deep Western bituminous coals was investigated in 1979 during another relatively small UCG trial near Pricetown, West Virginia where underground gasification was performed at the depth of $270 \mathrm{~m}$. The experiment lasted for more than 118 days with more than 200 tones of coal gasified. Another series of UCG experiments was conducted near Hoe Creek, Wyoming in 19761979. The site selection, with relatively shallow coal seam located at the depth of around $40 \mathrm{~m}$, was not particularly good but provided an opportunity for close monitoring and study of the process. This series of experiments had three trials, Hoe Creek I, II and III. Explosive fracturing of coal was attempted in the first experiment from this series but it was not any more successful than that in early Soviet trials. The Hoe Creek series became the first trials where oxygen/steam mixture was used on a significant scale and with a reasonable success. The data obtained in these trials were particularly instrumental for the further development of UCG technology. UCG in steeply dipping seams was demonstrated in a series of trials conducted near Rawlins, Wyoming in 1979-1981. The use of oxygen injection was particularly successful in these trials producing high-quality syngas suitable for manufacturing synthetic fuels. The gasification process took place at a depth exceeding $100 \mathrm{~m}$ and produced encouraging results in many 
respects.

A new UCG method called CRIP (controlled retracting injection point) was invented in the Centralia series of UCG trials (Washington, 1981-1983). A continuous change in the geometry of an underground gasifier may result in deterioration of syngas quality if the process is not properly adjusted. In Soviet UCG, this problem was solved by changing the injection and/or production points to new wells (one may recall that this idea was mentioned in the original Betts patent) while CRIP offers an alternative approach of using the same injection pipe but moving the injection point into the virgin seam. For this purpose, the CRIP injection pipe is directed along the seam through an inclined-horizontal borehole. The CRIP approach certainly has practical advantages: a single injection pipe accesses a larger volume of coal which is particularly important for gasification of deep seams and the injection point can be adjusted more often without a need to drill a long borehole from the surface. It needs to be noted that CRIP offers fewer control points and this may complicate large-scale operations using this method. In the original implementation of CRIP, the injection point was moved by inserting a gas burner and burning the liner at a desired location. This may seem a bit crude but, in principle, CRIP can involve more elaborate ways of controlling the injection point. The results obtained with the use of CRIP are very encouraging, but the method still needs to be tested on a large scale.

High quality syngas was consistently obtained in most of the American trials of this period, especially with the use of oxygen as the gasification agent. Oxygen/steam-generated syngas obtained by UCG is most suitable for production of inexpensive synthetic fuels. The UCG effort was, however, hampered by detection of groundwater contaminants in some cases. Although this happened only in a very small minority of the trials and was the result of obvious mistakes in site selection and operation, negative publicity was generated. The largest UCG trial of the program - Rocky Mountain — was conducted in 1987-1988. This trial was subject to scrupulous monitoring specifically designed to test the environmental and technological performance of UCG and was completed with excellent results. Two gasifiers, one with conventional vertical wells and the other one using CRIP were operated in close proximity. A mixture of oxygen and steam was used as an injection agent and high quality syngas was consistently produced, while more than 15 thousand tones of coal were gasified. The Rocky Mountain test clearly demonstrated that the UCG technology is ready for pilot-scale operations in America [5]. Among two practical options - moving UCG program to a larger scale or closing it down - the latter option was selected under the continuing pressure of low oil prices. The program was closed in 1989 and a significant fraction of the accumulated experience was lost.

\section{UCG Surge}

The interest in UCG surged again in the recent years. Unlike all major UCG programs of the 20th century, this unprecedented interest is mainly stimulated by private capital in response to record-high oil and energy prices. As result of this surge, knowledge of UCG is sought again and more than 30 trials are conducted or planned in Australia, China, India, South Africa, New Zealand, Canada and the USA. Many of these trials are carried out under technological auspices of Ergo-Exergy - the leading supplier of modern commercial UCG technology and the holder of proprietary rights for the process called $\varepsilon \mathrm{UCG}[2]$. 


\section{Conclusions}

While the idea of in situ gasification of coal was mentioned first by Siemens and then, in the form representing more modern understanding of UCG, by Mendeleev, it was Betts who made the intellectual breakthrough that can be called the invention of UCG. Betts's ideas are visible in first successful experiments in UCG and represent the beginning of highly sophisticated modern UCG technology. Although his role was later overshadowed by Ramsay, the patents granted to Betts in 1910 display many deep thoughts that are relevant even today.

The possibility of conducting UCG experiments was first mentioned by Mendeleev in 1899, although these experiments were unlikely to succeed if they were attempted. Ramsay prepared the first UCG experiment near Durham, UK but was not able to start this experiment due to the outbreak of the war in 1914. This experiment was intended to gasify coal in a channel of a significant scale and conceptually followed Bett's ideas. As far as we can judge from the available information, this experiment, if conducted, did have a reasonable chance of success. Ramsay did not attempt to use the blind borehole method (also suggested by Betts), as was later assumed in numerous publications.

The first UCG trial was conducted at the Krutova mine in Moscow coal basin in March, 1933. This experiment was unsuccessful not only due to poor preparations but also due to inherent problems of the chamber method. This and other chamber experiments followed understanding of UCG (or in situ gasification) introduced by Siemens.

The first successful UCG experiment took place in Lisichansk (Donetsk Basin) on April 24, 1934. This experiment used stream gasification and lasted only for 3 hours. The first UCG experiment without underground access (no man underground) commenced on September 5, 1934 in Lisichansk. This experiment produced syngas for 4 days and used the blind borehole method. Donetsk Institute of Coal Chemistry (DUKhI) provided technology for both of the Lisichansk experiments. The scales of these experiments were relatively small. Both of the DUKhI experiments in Lisichansk had conceptual similarities with the gasification schemes suggested by Betts and used or discussed by Ramsay.

The first successful pilot-style UCG operation began in Gorlovka (Donetsk Basin) on February 8, 1935. This operation used a new stream method designed by DUKhI. A method for pilot-scale shaftless gasification was experimentally discovered at Tula (Podmoskovnaia) UCG station in 1941. All these and consequent developments in UCG followed Mendeleev-Betts understanding of this concept.

After initial difficulties were overcome, the basis of UCG technology was built during the peak of Soviet UCG program in the 1950s and 1960s and significantly upgraded in American UCG program of the 1970s and 1980s. Past experience in UCG development indicates that optimal solutions for gasifying coal underground have always existed, but finding these solutions was a difficult task. Even in the best-prepared trials of the past, UCG pioneers could obtain only very limited information about the processes underground and most advances were achieved step by step through trial and error. UCG was being developed at times when the technological level was insufficient for rapid progress in the area. Over the years, these extensive efforts have nevertheless resulted in a workable technology that can be used on a large scale. The UCG technology has been proven but still requires a lot of care in its implementation. Two main conclusions can be drawn form the past UCG experience: (1) importance of specialized knowledge and understanding of the process and (2) importance of advanced monitoring 
and instrumentation. Good understanding allows us to move forward efficiently and quickly without repeating past mistakes and conducting conceptually flawed expensive experiments. Advanced monitoring enables quick diagnostics and computer-assisted, efficient control over the UCG processes. These opportunities were not available to the pioneers of UCG but we can use them and the potential benefits of UCG become even more convincing.

\section{References and Notes}

1. Coal smoke abatement. The Times, March 25, 1912.

2. Blinderman, M.S.; Anderson, B. Underground coal gasification for power generation: Efficiency and $\mathrm{CO}_{2}$-emissions. Proc. 12th International Conference on Coal Science, Cairns, Australia, November 2-6, 2003; Paper No. 13C1.

3. Friedmann, S.J. Carbon sequestration. Proc. 2006 Energy Symposium, Madison, WI, USA, 2006.

4. Case study B2O - Electricity production using underground coal gasification; Technical report, BHP Billiton: Newcastle, Australia, 2002.

5. Lindblom, S.R.; Smith, V.E. Rocky Mountain 1 Underground Coal Gasification Test, Hanna, Wyoming, Groundwater Evaluation; Technical Report DOE/MC/25038-36523, Western Research Institute, Laramie, WY, USA, 1993.

6. Ignatieff, A. Underground gasification of coal: Review of progress. Trans. Can. Inst. Mining Met. Mining Soc. Nova Scotia 1949, LII, 265-271.

7. Olness, D.U.; Gregg, D.W. The historical development of underground coal gasification; Technical Report UCRL-52283, California University, Lawrence Livermore Lab: Livermore, CA, USA, 1977.

8. Jolley, L.J.; Booth, N. The underground gasification of coal. Survey of the literature. Fuel 1945, 24, 31-37, 73-79.

9. Siemens, C.W. On the regenerative gas furnace as applied to the manufacture of cast steel. J. Chem. Soc. 1868, 21, 279-310,

10. Mendeleev, D.I. Collected Works XI; Akademiya Nauk SSSR: Moscow, USSR, 1949.

11. Mendeleev, D.I. Collected works XII; Akademiya Nauk SSSR: Moscow, USSR, 1949.

12. Betts, A.G. Method of utilizing buried coal, U.S. Patent 947,608, filed 1906, issued 1910.

13. Betts, A.G. Process of gasifying unmined coal, Canadian Patent 123,068, filed 1909, issued 1910.

14. Betts, A.G. An improved process for utilizing unmined coal, UK Patent 21674, filed 1909, issued 1910.

15. Betts, A.G. Lead Refining by Electrolysis; Wiley: New York, NY, USA, 1908.

16. Sir G. Askwith on the industrial outlook. The Times, June 7, 1912.

17. Lenin, V.I. A great technical achievement. Pravda, April 21, 1913; p. 91.

18. How Sir William Ramsay would dispense with the coal miners. Gas World, March 1912, pp. $422-432$.

19. Kirichenko, I.P. Results and prospects of subterranean gasification of coal. Ugol 1936, 124, 7-15.

20. Memorial to the late Sir William Ramsay. Nature 1916, 98, 197.

21. An Account of the Strata of Northumberland and Durham; North of England Institute of Mining and Mechanical Engineers: Newcastle upon Tyne, UK, 1894; Vol. S-T. 
22. Watson, K.D. The chemist as expert: the consulting career of Sir William Ramsay. AMBIX 1995, $42,143-159$.

23. Tilden, W.A. Sir William Ramsay; Memorials of his life and work; Macmillian: London, UK, 1918.

24. Travers, M.W. A Life of Sir William Ramsay; Edward Arnold: London, UK, 1956.

25. Sazonov, N.I. Summary of the first experimental results of subterranean gasification of coal. Khimia tverdogo topliva 1935, vi, 17-28.

26. Chernyshev, A.B. Underground coal gasification and Academy of Science USSR. Vestnik Akademii Nauk SSSR 1938, 9-10, 44-49.

27. Bakulev, G.D. Podzemnaia gazifikatsiia uglei v SSSR i za rubezhom; Ugletechizdat: Moscow, USSR, 1957.

28. Kirichenko, I.P.; Ton, V.S. Underground gasification at the Lisichansk mine. Gornij zhurnal 1935, 7, 10-19; 8, 10-21; 9, 15-20.

29. Blinderman, M.S.; Saulov, D.N.; Klimenko, A.Y. Forward and reverse combustion linking in underground coal gasification. Energy 2008, 33, 446-454.

30. Grindler, B.F. What really happened at Leninsk. Ugol' Vostoka 1935, 5, 14-15.

31. Korobchanskij, I.E.; Skafa, P.V.; Matveev, V.A.; Filipov, D.I.; Kruchkov, Ia.P.; Belikov, V.P.; Krym, V.S.; Demidkin, I.I.; Khlebnikov, V.V.; Zhovner, K.; Brozin, A.A.; Zaharov, T.A.; Kulish, E.D.; Antoshevsky, I.I. Method of underground gasification of hard fuels, USSR Patent 947,608, filed 1934, issued 1938.

32. Kozlov, A.L.; Nurshanov, V.A.; Pronin, V.N.; Nikitenko, E.A.; Riadchik, I.I.; Slansky, D.A.; Staroselsky, V.I.; Suslikov, E.N; Frolov, A.N.; Khalatin, V.I.; Khalif, A.L.; Shor, L.D. The Earth's Natural Fuel. Nedra: Moscow, USSR, 1981.

33. Sir Alexander Gibb and Partners. The underground gasification of coal. Report on the work done in Great Britain. Sir Isaac Pitman and Sons Ltd.: London, UK, 1964.

34. Burton, E.; Friedmann, J.; Upadhye, R. Best practices in underground coal gasification; Technical report, Lawrence Livermore National Lab: Livermore, CA, USA, 2007.

(c) 2009 by the authors; licensee Molecular Diversity Preservation International, Basel, Switzerland. This article is an open-access article distributed under the terms and conditions of the Creative Commons Attribution license (http://creativecommons.org/licenses/by/3.0/). 